\title{
Risk factors for mortality and mortality rates in interstitial lung disease patients in the intensive care unit
}

\author{
Julio A. Huapaya ${ }^{1,2}$, Erin M. Wilfong ${ }^{3,4}$, Christopher T. Harden ${ }^{5}$, Roy G. Brower ${ }^{2}$ \\ and Sonye K. Danoff ${ }^{2}$
}

Affiliations: ${ }^{1}$ Division of Internal Medicine, MedStar Georgetown University Hospital, Washington, DC, USA. ${ }^{2}$ Division of Pulmonary and Critical Care Medicine, Johns Hopkins University School of Medicine, Baltimore, MD, USA. ${ }^{3}$ Division of Pulmonary and Critical Care Medicine, Vanderbilt University Medical Center, Nashville, TN, USA. ${ }^{4}$ Division of Rheumatology, University of California, San Francisco, CA, USA. ${ }^{5}$ Division of Pulmonary, Critical Care and Sleep Medicine, University of Florida College of Medicine, Gainesville, FL, USA.

Correspondence: Sonye Danoff, Division of Pulmonary and Critical Care Medicine. Johns Hopkins University School of Medicine, 1830 Building, 1830 East Monument St, Baltimore, MD 21205, USA. E-mail: sdanoffajhmi.edu

@ERSpublications

Elevated APACHE score, hypoxaemia and mechanical ventilation are risk factors for mortality in ILD. No increased mortality was found with steroid use. Evidence on advanced age is inconclusive. Survival may be improving over time, but still remains high. http://ow.ly/6F1d30mijdy

Cite this article as: Huapaya JA, Wilfong EM, Harden CT, et al. Risk factors for mortality and mortality rates in interstitial lung disease patients in the intensive care unit. Eur Respir Rev 2018; 27: 180061 [https:// doi.org/10.1183/16000617.0061-2018].

ABSTRACT Data on interstitial lung disease (ILD) outcomes in the intensive care unit (ICU) is of limited value due to population heterogeneity. The aim of this study was to examine risk factors for mortality and ILD mortality rates in the ICU.

We performed a systematic review using five databases. 50 studies were identified and 34 were included: 17 studies on various aetiologies of ILD (mixed-ILD) and 17 on idiopathic pulmonary fibrosis (IPF). In mixed-ILD, elevated APACHE score, hypoxaemia and mechanical ventilation are risk factors for mortality. No increased mortality was found with steroid use. Evidence is inconclusive on advanced age. In IPF, evidence is inconclusive for all factors except mechanical ventilation and hypoxaemia. The overall inhospital mortality was available in 15 studies on mixed-ILD (62\% in $2001-2009$ and $48 \%$ in $2010-2017$ ) and 15 studies on IPF (79\% in 1993-2004 and 65\% in 2005-2017). Follow-up mortality rate at 1 year ranged between $53 \%$ and $100 \%$.

Irrespective of ILD aetiology, mechanical ventilation is associated with increased mortality. For mixedILD, hypoxaemia and APACHE scores are also associated with increased mortality. IPF has the highest mortality rate among ILDs, but since 1993 the rate appears to be declining. Despite improving in-hospital survival, overall mortality remains high.

\section{Introduction}

The interstitial lung diseases (ILD) encompass over 200 different entities, sharing common clinical features of progressive inflammation with variable scarring of the interstitium and alveoli [1]. The associated deterioration in lung function leads to both substantial morbidity and mortality. Acute exacerbation of ILD is defined as an acute respiratory deterioration characterised by evidence of new widespread alveolar

\section{This article has supplementary material available from err.ersjournals.com}

Received: July 082018 | Accepted after revision: Oct 052018

Provenance: Submitted article, peer reviewed.

Copyright CERS 2018. ERR articles are open access and distributed under the terms of the Creative Commons Attribution Non-Commercial Licence 4.0. 
infiltrates [2]. While best characterised in idiopathic pulmonary fibrosis (IPF), acute exacerbations are relevant in other forms of ILD and often lead to intensive care unit (ICU) admission [3]. Notably, progression of disease and infections are the most common causes of ICU admissions in patients with IPF [3]. However, there is a paucity of data on ICU outcomes in patients with ILD. Research on ICU mortality has been complicated by evolving diagnostic guidelines [4-6], which has led to significant variation in inclusion criteria from one study to the next. Ultimately, this makes it difficult for clinicians to provide relevant information on prognosis and outcomes to patients based on findings in a given study.

IPF is the most common form of idiopathic interstitial pneumonia (IIP) [5]. MALLICK et al. [7] reported an overall ICU mortality of $87 \%$ in ventilated patients from studies published before 2006. Many studies in the ILD literature focus only on ICU outcomes in IPF because this diagnosis generally carries the worst prognosis in ILD [8]. However, it is not clear that other forms of ILD confer a similar prognosis. Making this distinction is difficult, but clinically important as articles considering ICU outcomes in mixed-ILD populations often include patients with IPF.

Given the heterogeneity of disease and diagnosis, various stages of disease and the myriad of triggers for ICU admission [9], our objective was to review current knowledge on variables associated with increased risk of mortality in the ICU, evaluate the factors that affect clinical outcomes in the ICU, determine mortality rates and identify important areas for future research.

\section{Methods}

\section{Search strategy and selection criteria}

We conducted a systematic review with relevant papers identified via PubMed, Scopus, Cochrane, Embase and Scielo searches for English and Spanish articles with the keywords "ILD", "interstitial pneumonia", "interstitial pneumonitis", "IIP", "IPF", "intensive care unit" and "outcomes", among other terms (supplementary material e-table 1). Our target population was adult patients with ILD admitted to the ICU for whom mortality data were available. Patients who presented in acute respiratory failure and then underwent a lung biopsy during their ICU stay were included. Patients admitted to the ICU due to complications from elective lung biopsy were excluded from this review. Studies on patients with acute interstitial pneumonia were also excluded as prior review articles on this topic have been previously published $[10,11]$.

The complete search strategy was performed on November 21, 2017. All titles and abstracts were evaluated for further review independently by two authors (figure 1). A total of 348 unique articles were reviewed. Of these, 298 were excluded because: ICU outcomes were not evaluated; different target populations were included (acute respiratory distress syndrome, lung transplant, children, etc.); they consisted of case reports of less than three patients; or were letter to the editor and review articles. Conference abstracts were not reviewed if they had not been published in the aforementioned databases. Of 50 articles reviewed in full text, 16 articles were excluded (lung biopsy for ILD: $n=4$; unknown lung infiltrates in the ICU: $n=4$; polymyxin and extracorporenal membrane oxygenation: $n=2$; acute interstitial pneumonia: $n=2$; coal worker pneumoconiosis: $\mathrm{n}=1$; acute respiratory distress syndrome: $\mathrm{n}=1$; myositis: $\mathrm{n}=1$; and use of bronchoscopy: $\mathrm{n}=1$ ). In total, 34 studies were identified for inclusion in this review (table 1). Studies of patients with IPF were separated from those with heterogeneous patient population (mixed-ILD). 17 papers included only IPF patients; the remaining 17 included mixed-ILD.

\section{Data extraction and quality assessment}

A data extraction form was developed for the purpose of the review and included research design, study sample, source of bias, data collection and follow-up rates. We did not use other tools available in the literature given that all the studies, except for one, presented retrospective information based on series of cases without a comparator group. Two authors (J.A. Huapaya and E.M. Wilfong) assessed the relevance of articles independently. Queries were resolved through discussion with the senior author (S.K. Danoff). No meta-analysis was considered because of the heterogeneity of the population included in the studies, lack of consistent evaluation of all the risk factors for mortality (the majority of studies only reported information on a few risk factors and did not mention others), lack of consistent analysis (only a few studies performed multivariate analysis) and a wide range of years included in the analysis of each study.

\section{Mortality rates estimation}

Mortality rates were extracted from each study at different time-points: ICU, in-hospital and follow-up mortality (3, 6 and 12 months). For simplicity of analysis, overall mortality included the available in-hospital and ICU mortality. Mean percentage of mortality rates was not used for the calculation of overall mortality as this could have represented a source of bias given different sample sizes. Therefore, the 
TABLE 134 studies on mixed-interstitial lung disease (IID) and idiopathic pulmonary fibrosis (IPF) included in the systematic review

$\begin{array}{lllcll}\text { First author [ref.] } & \text { Year } & \text { Country } & \begin{array}{c}\text { Patients } \\ \mathbf{n}\end{array} & \text { Patient population } & \text { Design }\end{array}$

\begin{tabular}{|c|c|c|c|c|c|}
\hline \multicolumn{6}{|l|}{ Mixed-ILD } \\
\hline CHURg [13] & 2007 & Canada & 12 & $\begin{array}{l}9 \text { patients with UIP, } 2 \text { with NSIP, } 1 \text { chronic HP } \\
\text { undergoing lung biopsy for unknown cause of ARF }\end{array}$ & Retrospective \\
\hline Fernandez-Perez [14] & 2008 & USA & 94 & ILD patients admitted to ICU requiring IMV for $>24 \mathrm{~h}$ & Retrospective \\
\hline GAUDRY [16] & 2014 & France & 27 & IPF or fibrosing idiopathic NSIP who required IMV & Retrospective \\
\hline GonCALVES [17] & 2016 & Portugal & 37 & ILD ICU admissions & Retrospective \\
\hline GUNGOR [18] & 2013 & Turkey & 120 & ILD ICU admissions & Retrospective \\
\hline MARTINEZ [19] & 2015 & Australia & 36 & $\begin{array}{c}\text { Patients admitted to the ICU with respiratory } \\
\text { insufficiency secondary to IIP }\end{array}$ & Retrospective \\
\hline Molina-Molina [20] & 2003 & Spain & 20 & ILD ICU admissions & Retrospective \\
\hline OLson [21] & 2008 & USA & 4 & Fibrotic HP undergoing AE & Retrospective \\
\hline Osman [22] & 2017 & Egypt & 91 & ILD RICU admissions & Perspective \\
\hline PARK [23] & 2007 & $\begin{array}{l}\text { South } \\
\text { Korea }\end{array}$ & 10 & Biopsy proven non-IPF ILD patients & Retrospective \\
\hline YokoYama [27] & 2012 & Japan & 38 & $\begin{array}{c}\text { Rapidly progressing interstitial pneumonia treated with } \\
\text { early NIMV }\end{array}$ & Retrospective \\
\hline ZAFRANI [28] & 2014 & France & 83 & ILD-associated ARF & Retrospective \\
\hline \multicolumn{6}{|l|}{ IPF } \\
\hline AKIRA [29] & 1997 & Japan & 17 & Accelerated deterioration of IPF & Retrospective \\
\hline AL-HAMEED [30] & 2004 & Canada & 25 & AE-IPF ICU admissions & Retrospective \\
\hline AMBROSINI [31] & 2003 & Italy & 5 & AE-IPF ICU admissions & Retrospective \\
\hline BLIVET [32] & 2001 & France & 15 & IPF admitted for respiratory failure & Retrospective \\
\hline KІм [33] & 2006 & Korea & 11 & Biopsy-proven AE-IPF & Retrospective \\
\hline KONDOH [34] & 1993 & Japan & 3 & $A E-I P F$ & Retrospective \\
\hline MoLLICA [35] & 2010 & Italy & 34 & IPF patients undergoing IMV & Retrospective \\
\hline Nava [36] & 1999 & Italy & 7 & End-stage IPF patients undergoing IMV & Retrospective \\
\hline OdA [37] & 2016 & Japan & 209 & $\begin{array}{l}\text { IPF with ARF requiring ventilation and high-dose } \\
\text { steroids }\end{array}$ & Retrospective \\
\hline VIANELLO [43] & 2014 & Italy & 18 & IPF patients receiving NIMV for ARF & Retrospective \\
\hline YoKOYAMA [44] & 2010 & France & 83 & ILD-associated ARF & Retrospective \\
\hline
\end{tabular}

UIP: usual interstitial pneumonia; NSIP: nonspecific interstitial pneumonia; HP: hypersensitivity pneumonitis; ARF: acute respiratory failure; ICU: intensive care unit; IMV: invasive mechanical ventilation; IIP: idiopathic interstitial pneumonia; AE: acute exacerbation; RICU: respiratory ICU; CTD: connective tissue disease; NIMV: noninvasive mechanical ventilation.

total number of deaths was calculated for each study and was then divided by the total number of patients at risk.

\section{Results}

One prospective and 33 retrospective studies (one that also reports 10 patients who were prospectively evaluated) [12] were included in the analysis (table 1). 26 studies included less than 50 patients, six studies included between 50 and 100 patients, and two studies included more than 100 patients. The largest cohort had 209 patients and the smallest one had only three patients. IPF specific data from the studies with mixed population was not available to be added to the IPF specific studies. Mixed-ILD patients included IPF, connective tissue disease (CTD)-ILD, drug-induced ILD, hypersensitivity pneumonitis, and 


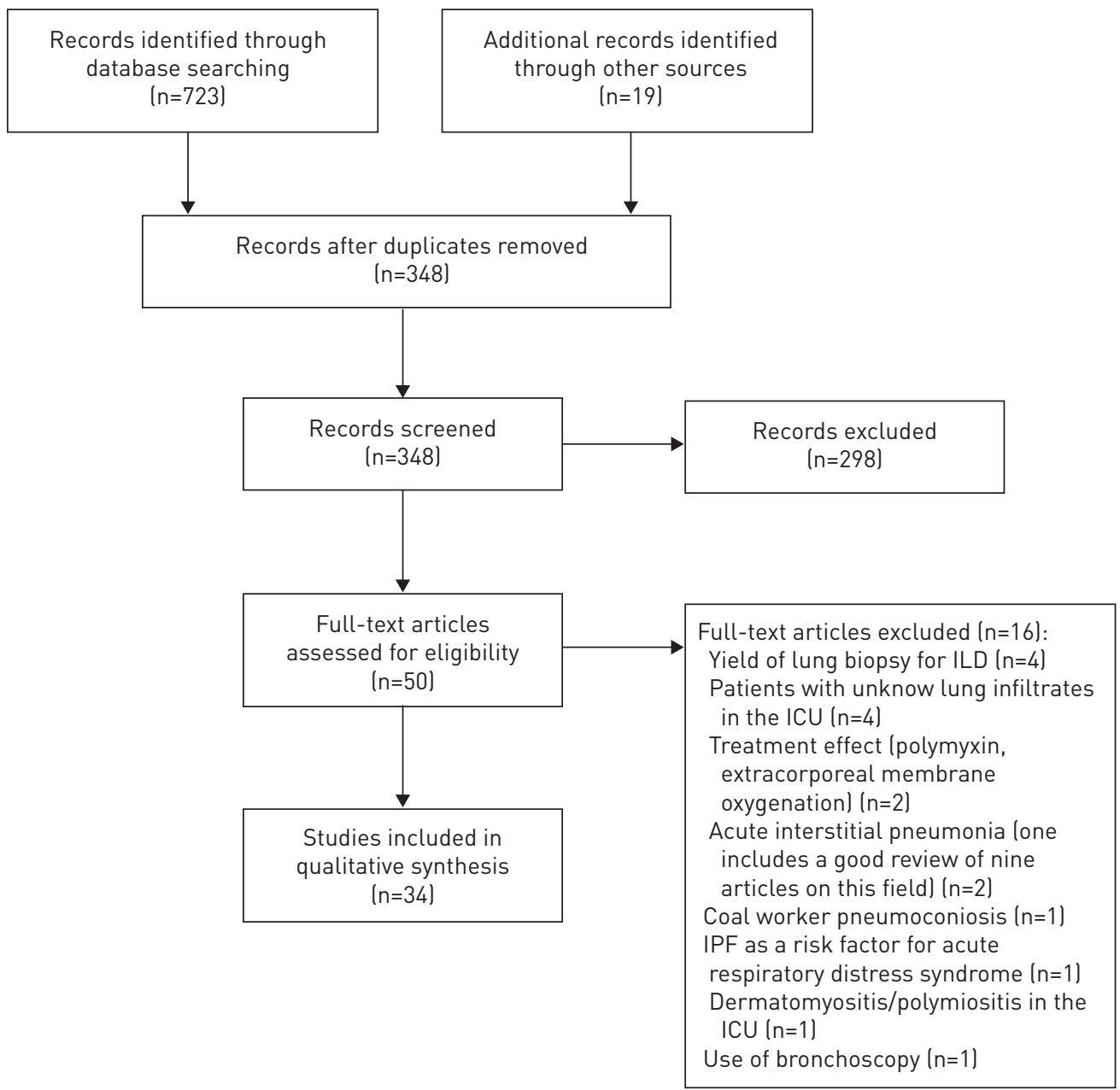

FIGURE 1 Flow diagram of study selection. ILD: interstitial lung disease; ICU: intensive care unit; IPF: idiopathic pulmonary fibrosis.

other aetiologies. Overall in-hospital mortality according to geographic regions is presented in supplementary material e-table 5 .

\section{Mortality in mixed-ILD studies}

Our review identified 780 patients with mixed causes of ILD in 17 studies [12-28]. 15 studies had information on ICU or in-hospital mortality, reporting a total of 685 patients. The remaining two studies had mortality at post-hospitalisation follow-up (2 and 3 months, respectively) [24, 25]. ICU admission occurred due to acute respiratory failure secondary to infections and disease progression in $30-75 \%$ of cases. $5-10 \%$ of admissions occurred due to pneumothorax, pulmonary embolism, congestive heart failure, were drug induced or due to other causes. The overall in-hospital mortality (15 studies) was 52\%. Notably, half of these patients had IPF (table 2). Stratifying the studies according to their year of publication showed the overall in-hospital calculated mortality was 62\% during the period 2001-2009 and 48\% during 2010-2017 (supplementary material e-table 3). Cut-offs for different years were used to evaluate if this trend was consistent throughout different periods (supplementary material e-table 4). Notably, mortality increases with time post hospitalisation (table 2). Some studies reported 1-year mortality of 54-59\% [14, 28], whereas others reported 1-year mortality of $85-96 \%[12,16]$.

\section{Mortality in IPF studies}

17 studies of IPF included 554 patients (table 2) [3, 29-44]. 15 of these studies had information on ICU or in-hospital mortality accounting for 526 patients; the remaining two studies had mortality at post-discharge follow-up (2 and 3 months, respectively) [29, 44]. The overall in-hospital mortality of the 15 studies was 68\%, which is lower than previously reported [7]. Notably, studies from the 1990s reported mortality rates around $80-100 \%[30,32,36]$, whereas recent studies in large populations reported 
TABLE 2 Intensive care unit (ICU), in-hospital and follow-up mortality in patients with mixed-interstitial lung disease (ILD) and idiopathic pulmonary fibrosis (IPF)

\begin{tabular}{|c|c|c|c|c|c|c|c|c|c|}
\hline First author [ref]. & $\begin{array}{l}\text { Inclusion years } \\
\text { month/year }\end{array}$ & Total $^{+}$ & Included $^{\S}$ & IPF & $\begin{array}{l}\text { Overall } \\
\text { deaths }\end{array}$ & $\begin{array}{c}\text { ICU } \\
\text { mortality \% }\end{array}$ & $\begin{array}{l}\text { In-hospital } \\
\text { mortality \% }\end{array}$ & $\begin{array}{c}\text { Overall } \\
\text { in-hospital } \\
\text { mortality \% }\end{array}$ & $\begin{array}{l}\text { Follow-up } \\
\text { mortality \% }\end{array}$ \\
\hline \multicolumn{10}{|l|}{ Mixed-ILD } \\
\hline ChuRg [13] & Not provided & 12 & 12 & 9 & 2 & & 13 & 13 & 36 (11 months) \\
\hline FERNANDEZ-PEREZ [14] & $02 / 2002-07 / 2006$ & 94 & 94 & 30 & 50 & & 53 & 53 & 59 (1 year) \\
\hline FumEAUx $[15]^{\#}$ & $12 / 1996-03 / 2001$ & 14 & 14 & 11 & 14 & 100 & 100 & 100 & \\
\hline GAUDRY [16] & 01/2002-04/2009 & 27 & 27 & 22 & 23 & 77 & 85 & 85 & 96 (1 year) \\
\hline Goncalves [17] & $01 / 2004-05 / 2015$ & 37 & 37 & 5 & 23 & 62 & & 62 & 81 (1 month) \\
\hline GUNGOR [18] & $01 / 2008-12 / 2010$ & 120 & 120 & 96 & 72 & 60 & & 60 & \\
\hline HUIE [12] & $06 / 2006-04 / 2009$ & 27 & 27 & 13 & 17 & & 63 & 63 & $\begin{array}{l}74 \text { (2 months), } \\
78 \text { (6 months), } 85 \text { (1 year) }\end{array}$ \\
\hline MARTINEZ [19] ${ }^{\#}$ & $12 / 2007-12 / 2013$ & 36 & 36 & 25 & 25 & 55 & 69 & 69 & \\
\hline Molina- Molina [20] & $01 / 1986-06 / 2002$ & 20 & 20 & 14 & 20 & 95 & 100 & 100 & \\
\hline OLson $[21]$ & $01 / 2005-01 / 2007$ & 4 & 4 & 0 & 4 & & 100 & 100 & \\
\hline Osman [22] & $01 / 2013-07 / 2015$ & 91 & 91 & 68 & 9 & & 10 & 10 & \\
\hline PARK [23] & 1993-04/2006 & 10 & 10 & 0 & 6 & & 60 & 60 & 60 (6 months) \\
\hline TACHIKAWA [24] & 1/2003-12/2009 & 62 & $\mathrm{NI}$ & $\mathrm{NI}$ & & & & & 90 (3 months) \\
\hline TомІІ [25] & $10 / 2001-09 / 2006$ & 33 & $\mathrm{NI}$ & $\mathrm{NI}$ & & & & & 46 (2 months) \\
\hline VIAL-DupuY [26] & 7/1993-12/2009 & 72 & 72 & 16 & 33 & & 46 & 46 & \\
\hline YoKOYAMA [27] & $01 / 2005-12 / 2010$ & 38 & 38 & 16 & 21 & & 54 & 54 & \\
\hline ZaFRANI [28] & $01 / 2002-03 / 2013$ & 83 & 83 & 9 & 34 & & 41 & 41 & 54 (1 years) \\
\hline Total & & 780 & 685 & 334 & 353 & & & & \\
\hline \multicolumn{10}{|l|}{ IPF } \\
\hline AKIRA [29] & Not provided & 17 & $\mathrm{NI}$ & $\mathrm{NI}$ & & & & & 48 (3 months) \\
\hline AL-HAMEED [30] & $09 / 1988-12 / 2001$ & 25 & 25 & 25 & 24 & 84 & 96 & 96 & 100 (1 year) \\
\hline AMBROSINI [31] & $05 / 2001-06 / 2002$ & 5 & 5 & 5 & 4 & 80 & & 80 & 80 (1.5 years) \\
\hline BLIVET [32] & 01/1989-06/1998 & 15 & 15 & 15 & 13 & 73 & 86 & 86 & \\
\hline KIM [33] & 01/1990-09/2003 & 11 & 11 & 11 & 7 & 70 & 63 & 63 & 82 (3 months) \\
\hline KonDOH [34] & Not provided & 3 & 3 & 3 & 0 & 0 & 0 & 0 & 33 (6 months) \\
\hline MoLLICA [35] & $01 / 2000-01 / 2007$ & 34 & 34 & 34 & 29 & & 85 & 85 & 97 (6 months) \\
\hline NAVA [36] & Not provided & 7 & 7 & 7 & 6 & 85 & & 85 & \\
\hline OdA [37] & $04 / 2010-03 / 2013$ & 209 & 209 & 209 & 138 & & 66 & 66 & \\
\hline PAPIRIS [38] & 2007-06/2013 & 17 & 17 & 17 & 11 & 65 & & 65 & \\
\hline PARAMBIL [39] & $01 / 1996-12 / 2002$ & 7 & 7 & 7 & 6 & 86 & 86 & 86 & \\
\hline RANGAPPA [3] & $01 / 1996-12 / 2006$ & 24 & 24 & 24 & 22 & 67 & 92 & 92 & \\
\hline SAYDAIN [40] & $01 / 1995-07 / 2000$ & 38 & 38 & 38 & 23 & 45 & 61 & 61 & \\
\hline Song [41] & 1990-2009 & 90 & 90 & 90 & 45 & & 50 & 50 & \\
\hline SteRn [42] & 09/1990-10/1999 & 23 & 23 & 23 & 22 & & 96 & 96 & \\
\hline VIANELLO [43] & $01 / 2005-04 / 2013$ & 18 & 18 & 18 & 10 & 55 & & 55 & $\begin{array}{l}86 \text { (3 months), } \\
100 \text { (1 year) }\end{array}$ \\
\hline YokoYama $[44]^{\pi}$ & 04/1998-06/2004 & 11 & $\mathrm{NI}$ & $\mathrm{NI}$ & & & & & $\begin{array}{l}55 \text { (3 months), } \\
70 \text { (6 months) }\end{array}$ \\
\hline Total & & 554 & 526 & 526 & 360 & & & & \\
\hline
\end{tabular}

Data are presented as $\mathrm{n}$, unless otherwise stated. $\mathrm{NI}$ : not included in the overall mortality analysis. ${ }^{\#}$ : patients with radiological diagnosis of usual interstitial pneumonia who were not labelled as IPF in the original study but were considered IPF for our analysis; ": these studies provided information on follow-up mortality only; ${ }^{+}$: all the patients of 17 studies included in the systematic review; ${ }^{\S}$ : number of patients included in the ICU and in-hospital mortality analysis, [24, 25, 29, 44] were excluded.

mortality rates of $50-66 \%[37,41]$. Reasons for ICU admissions were similar as for mixed-ILD. Stratifying the 15 studies according to their year of publication, the overall in-hospital mortality was $79 \%$ during the period 1993-2004 and 65\% during 2005-2017 (supplementary material e-table 3). Similarly to mixed-ILD studies, different year cut-offs were used to repeat the analysis (supplementary material e-table 4). Despite improving overall survival, mortality increased over time post hospitalisation as two studies reported $100 \%$ mortality at 1-year of follow-up (table 2) [30,43]. Notably, the cause of death post hospitalisation is not available and, therefore, it is not possible to assign these deaths directly to IPF.

Variables associated with increased mortality

The current evidence on different factors and their association with mortality is presented in the following sections (table 3 ). 
TABLE 3 Risk factors for overall mortality in patients with mixed-interstitial lung disease (ILD) and idiopathic pulmonary fibrosis (IPF) in the intensive care unit (ICU)

\begin{tabular}{|c|c|c|c|c|}
\hline Risk factor & $\begin{array}{l}\text { Studies in mixed-ILD } \\
\text { patients }\end{array}$ & Mortality association & $\begin{array}{l}\text { Studies in IPF } \\
\text { patients }\end{array}$ & Mortality association \\
\hline Advanced age & $\begin{array}{c}2 \text { positive studies } \\
{[14,27]} \\
5 \text { negative studies } \\
{\left[12,18,22,26,28^{+}\right]}\end{array}$ & Inconclusive: 1 large study in each side & $\begin{array}{l}1 \text { positive study [37], } \\
4 \text { negative studies } \\
{\left[3,41,43^{\S}, 44\right]}\end{array}$ & $\begin{array}{l}\text { Inconclusive: } 1 \text { large study found an association; } \\
\text { another large study and four small studies did not }\end{array}$ \\
\hline Elevated APACHE score & $\begin{array}{c}3 \text { positive studies } \\
{[12,14,18]} \\
3 \text { negative studies } \\
{\left[17,26,27^{f}\right]}\end{array}$ & Large studies report a significant association & $\begin{array}{c}1 \text { positive study [3], } \\
2 \text { negative studies } \\
{\left[43^{\S}, 44\right]}\end{array}$ & Inconclusive: studies with small sample size \\
\hline $\begin{array}{l}\text { Histology showing diffuse } \\
\text { alveolar damage }\end{array}$ & $\begin{array}{l}3 \text { studies } \\
{[12,13,21]}\end{array}$ & $\begin{array}{l}\text { Small studies report high mortality in the univariate } \\
\text { analysis; not enough data to assess for an association }\end{array}$ & $\begin{array}{l}3 \text { studies } \\
{[29,31,34]}\end{array}$ & $\begin{array}{l}\text { Small studies report high mortality in the univariate } \\
\text { analysis; not enough data to assess for an association }\end{array}$ \\
\hline Hypoxaemia & $\begin{array}{c}3 \text { positive studies } \\
{\left[14,22^{\# \#}, 27^{111}\right],} \\
1 \text { negative study [18f] }\end{array}$ & Large studies report a significant association & $\begin{array}{c}3 \text { negative studies } \\
{\left[41^{+}, 43^{\S}, 44\right]}\end{array}$ & $\begin{array}{c}\text { No association was found; } 2 \text { studies with }<20 \text { patients } \\
\text { each }\end{array}$ \\
\hline Mechanical ventilation ? & $\begin{array}{c}6 \text { positive studies } \\
{\left[12,14^{++}, 17,18,26,27\right]} \\
2 \text { negative studies } \\
{[22,28]}\end{array}$ & $\begin{array}{l}\text { Multiple studies report high mortality in the univariate } \\
\text { analysis; } 6 \text { studies report a significant association }\end{array}$ & & $\begin{array}{l}\text { Multiple studies report high mortality in the univariate } \\
\text { analysis; not enough data to assess for an association }\end{array}$ \\
\hline Steroids & $\begin{array}{c}3 \text { negative studies } \\
{\left[14,26^{\S \S}, 28^{+}\right]}\end{array}$ & $\begin{array}{l}\text { No association was found in } 3 \text { studies; } 1 \text { reported use } \\
\text { of steroids was a protective factor }\end{array}$ & 1 negative study & $\begin{array}{c}\text { Inconclusive: only } 1 \text { study with a small sample size is } \\
\text { available }\end{array}$ \\
\hline
\end{tabular}

APACHE: Acute Physiology And Chronic Health Evaluation; NIMV: noninvasive mechanical ventilation." : no bivariate analysis is provided due to the small sample sizes and high mortality reported in these studies. " : high rates of mortality associated with mechanical ventilation (70-100\% for IPF and $27-100 \%$ in mixed-ILD) precluded bivariate or multivariate analysis in more studies other than those reported in this table. ${ }^{+}$: an association was found in the bivariate analysis but not in the multivariate. ${ }^{\S}$ : no direct comparison between survivors and nonsurvivors. The study primary compared NIMV success group versus NIMV failure group. However, no patient died in the former group and all 10 died in the latter group. ${ }^{\prime}$ : a trend towards significance. \#\#: this study reported significantly lower arterial oxygen saturation but comparable arterial oxygen tension in nonsurvivors versus survivors (bivariate analysis only). १ा: significantly higher arterial oxygen tension/inspired oxygen fraction ratio in survivors versus nonsurvivors at the start of NIMV but not on admission. ${ }^{++}$: higher positive end-expiratory pressure was associated with increased mortality. $\S \S$ : this study showed that the use of steroids was a protective factor in the multivariate analysis. 
Age

Increased age has been evaluated as a risk factor of ICU mortality, especially in large studies [14, 18, 22, 26, 28, 37, 41]. In mixed-ILD, using multivariate analysis, FernANDEZ-Perez and co-workers [14] showed increasing age was a risk factor for in-hospital mortality (OR 1.07, 95\% CI 1.01-1.14) and 1-year mortality (HR 1.03, 95\% CI 1.00-1.05) in patients who required invasive mechanical ventilation (IMV). ҮокоуАмА and co-workers [27] demonstrated a significant association between younger age and hospital survival when evaluating patients with rapidly progressing interstitial pneumonia regardless of the cause of the underlying ILD. However, five other studies failed to replicate those results [12, 18, 22, 26, 28].

Data on age as a risk factor for mortality in IPF is also mixed. Three small studies of less than 25 patients each did not find an association between age and mortality [3, 43, 44]. However, in a study of 209 patients, ODA and co-workers [37] reported that patients aged $>80$ years had significantly increased ICU mortality compared to those aged $<60$ years (OR 2.94, 95\% $\mathrm{Cl} 1.044-8.303$ ). The study by Song and co-workers [41] does not support this finding when analysing age during acute exacerbation in 209 patients (OR 1.022, 95\% CI 0.969-1.078), but demonstrates that age was a prognostic factor on overall IPF survival after diagnosis (HR 1.017, 95\% CI 1.001-1.033).

\section{Hypoxaemia}

In mixed-ILD, three studies $[14,22,27]$ found an association between hypoxaemia and mortality and one study had a trend towards association [18]. Fernandez-PEREZ and co-workers [14] reported a significant difference $(\mathrm{p}<0.001)$ in arterial oxygen tension/inspiratory oxygen fraction $\left(\mathrm{PaO}_{2} / \mathrm{FIO}_{2}\right)$ ratio between survivors (median (interquartile range, IQR) 252 (158-388)) and nonsurvivors (median (IQR) 117 (71-182)). In the multivariate analysis, each 10-unit increase in the $\mathrm{PaO}_{2} / \mathrm{FIO}_{2}$ ratio was protective for in-hospital mortality (OR 0.93, 95\% CI 0.86-0.99) and 1-year survival (HR 0.96, 95\% CI 0.92-0.99). Үокочама and co-workers [27] also found a significantly higher $\mathrm{PaO}_{2} / \mathrm{FIO}_{2}$ ratio in survivors (mean \pm SD164.5 \pm 75.8$)$ versus nonsurvivors $(110.4 \pm 50.5)$ at the start of noninvasive mechanical ventilation (NIMV) but not on admission $(195.6 \pm 53.6$ versus $184.0 \pm 71.6, \mathrm{p}=0.851)$. Similarly, Osman and co-workers [22] found that low arterial oxygen saturation was significantly more frequent in nonsurvivors $(\mathrm{p}=0.02)$. In contrast, TACHIKAWA and co-workers [24] reported that the $\mathrm{PaO}_{2} / \mathrm{FIO}_{2}$ ratio was not a prognostic factor for 90-day survival (HR 0.995, 95\% CI 0.988-1.001) when correcting for age, sex, type of ILD, prior use of oxygen therapy and smoking history. In IPF studies, three studies failed to show an association between hypoxaemia and mortality [41, 43, 44]. The size of two studies was very small $(<20$ patients) and the third study $(n=90)$ found an association in the bivariate but not the multivariate analysis.

\section{Acute physiology and chronic health evaluation (APACHE) scores}

APACHE scores predicts ICU mortality based on the first ICU day [45]. Six studies in mixed-ILD patients reported APACHE scores and hospital mortality: three studies found a positive association [12, 14, 18] and one study showed a trend towards association [27]. HUIE and co-workers [12] report that an increase of 1 point in APACHE II score was associated with an OR of 1.05 (95\% CI 1.00-1.11, p=0.040) in 27 patients with fibrotic lung disease. GUNGOR and co-workers [18] report a median APACHE score of 19 (IQR 16-23) in survivors and 29 (IQR 23-36) in nonsurvivors $(\mathrm{p}=0.001)$. Similarly, FernandeZ-Perez and co-workers [14] evaluated mortality risk using the APACHE III scores and found a HR of 1.33 (95\% CI 1.18-1.50) with regards to hospital mortality (median of 57 in survivors and 78 in nonsurvivors). While not reaching statistical significance, Үокоунма and co-workers [27] showed a trend in association between APACHE II score and mortality with a mean score of 9.5 for survivors and 11.4 for nonsurvivors $(\mathrm{p}=0.056)$. It is important to note that age and $\mathrm{PaO}_{2}$, identified above as independent risk factors, are both components of the APACHE score and, thus, there may be overlap in their predictive roles. Two small studies found no association between APACHE and mortality $[17,26]$.

In IPF studies, only RANGAPPA and MoRAN [3] found significantly higher APACHE III scores in nonsurvivors (HR 1.02, 95\% CI 1.004-1.031). They reported a $2 \%$ increase in hazard per unit increase in APACHE III score. However, two small studies including 29 patients did not find an association [43, 44].

\section{Histology}

Older studies report a high number of biopsies (50-100\%) with diffuse alveolar damage and suggest it was a poor prognostic factor in patients with ILD in the ICU. Biopsies were mainly done for work-up for new unknown infiltrates $[12,13,21,29,31,33,34,39]$. However, no bivariate analysis was provided due to the small sample sizes and high mortality reported in these studies [13, 21, 29, 31]. Nowadays, biopsies are not routinely performed because lung biopsy in acute ILD is associated with increased in-hospital mortality (16\%) compared to elective biopsies (1.7\%) [46]. This higher mortality may be attributable to the severity of illness rather than to the biopsy itself. 


\section{Immunosuppression}

The use of immunosuppressant medications including steroids and cyclophosphamide, among others, is controversial in the treatment of ILD patients in the ICU, and the benefit likely depends on underlying ILD aetiology. Two large mixed-ILD studies did not find an association between steroid use and increased mortality $[14,28]$. In fact, a retrospective study found that use of high-dose steroids during ICU had a protective effect for in-hospital mortality (OR 0.19, 95\% CI 0.04-0.99) [26]. These authors suggest that steroids could be used once infection has been ruled out. However, it is important to highlight the number of patients who received steroids was higher in the groups that included conditions typically responsive to steroids such as CTD-ILD, hypersensitivity pneumonitis, vasculitis and drug-induced ILD. In light of these results, certain patients will likely benefit from this treatment, especially young patients with features suggestive of CTD-ILD or patients with ILD who do not have a significant amount of fibrosis [28].

In IPF patients, SoNG and co-workers [41] found that steroid use did not predict mortality in 90 patients with acute exacerbation of IPF $(0.828,95 \%$ CI $0.353-1.943)$. PAPIRIs and co-workers [38] advocate stopping all immunosuppression in patients experiencing an acute exacerbation and report a survival advantage; specifically, $65 \%$ of IPF patients who had not been exposed to steroids prior to admission were alive at 1 year, whereas only $17 \%$ were alive in the exposed group. It is possible that patients who had received steroids were initially more ill, especially because the use of IMV was significantly higher in the group who had been exposed to steroids (six out of nine patients compared to none of 12 in the non-exposed group). Similarly, a multivariate analysis by ODA and co-workers [37] demonstrated that the use of intravenous high-dose cyclophosphamide was associated with poor prognosis (OR 3.17, 95\% Cl 1.101-9.148). Interestingly, a recent observational study showed some benefit in patients with acute exacerbations of IPF who received rituximab and immunoglobulin [47].

\section{Mode of ventilation}

Invasive mechanical ventilation

Poor outcomes for ILD patients have been reported when respiratory failure requires IMV. In mixed-ILD, six studies showed increased mortality in IMV in the bivariate or multivariate analysis [12, 14, 17, 18, 26, 27]; whereas only two studies did not find an association $[22,28]$. Multiple studies report high mortality rates associated with IMV, ranging from $27 \%$ to $100 \%$ in the univariate analysis (supplementary material e-table 2). Furthermore, ZAFRANI and co-workers [28] showed that IMV was associated with 1-year mortality in a multivariate analysis (OR 5.18, 95\% CI 1.18-22.75). In IPF, data precluded calculation of ORs due to high rates of mortality associated with IMV, ranging from $70 \%$ to $100 \%$ (supplementary material e-table 2). Pooled analysis on mortality rates associated with IMV in mixed-ILD and IPF can be found in the supplementary material.

Two studies have specifically investigated the impact of IMV settings in ILD [3, 14]. High positive end-expiratory pressure (PEEP) defined as $>10 \mathrm{cmH}_{2} \mathrm{O}$ was associated with a decreased survival both during hospitalisation (OR 17.26, $\mathrm{p}<0.001)$ and at 12 month (OR 4.72, $\mathrm{p}<0.001)$ [14]. The benefits of low tidal volumes have not been assessed in prospective studies of ILD; however, some retrospective data does exist. GAUDRY and co-workers [16] raise the question of the positive effect of low tidal volumes $(5.9 \pm 1.3 \mathrm{~mL})$ for ILD as eight out of 27 patients were successfully weaned off the ventilator. However, FerNANDEZ-PEREZ and co-workers [14] reported lower tidal volumes in nonsurvivors (median (IQR) 7 (6-9) $\mathrm{mL} \cdot \mathrm{kg}^{-1}$ ) compared to survivors (median (IQR) $6(7-10) \mathrm{mL} \cdot \mathrm{kg}^{-1}$ ) although the authors acknowledge low tidal volumes were used inconsistently.

\section{Noninvasive mechanical ventilation}

NIMV has also been a subject of study in ILD. Some studies suggest that NIMV can prevent intubation and reduce mortality in some IPF patients [18, 25, 35, 44]. YOKOHAMA and co-workers [27] found that early initiation of NIMV in hypoxaemic patients suspected of having an acute exacerbation of ILD and initiation of NIMV on day one were associated with survival $(76.9 \%$ survivors versus $8.3 \%$ nonsurvivors, $\mathrm{p}<0.0001)$. Mollica and co-workers [35] found that NIMV significantly reduced the respiratory rate in comparison to admission (mean of 26 versus 36) and prevented intubation in five out of 19 patients but did not improve survival. A major limitation of this study, however, was a significant variation in disease severity between the patients who initially received NIMV (APACHE II 19.5 \pm 5.9 ) and IMV (APACHE II 24.2 \pm 6 ) [35]. Nonetheless, the authors concluded that NIMV might be beneficial for early intervention in less severe cases, as well as a means of palliation by decreasing respiratory rate. The use of NIMV in the setting of less severe respiratory failure was further supported by GUNGOR and co-workers [18] Individuals treated with non-continuous NIMV alone had a mortality rate of only $10.7 \%$ (out of 28 patients). Survival was particularly high among patients with an APACHE II score $<20$ supporting the use of NIMV in less severe presentations. A study of 11 acute exacerbation IPF patients showed that NIMV prevented intubation in five patients with severe hypoxaemia $\left(\mathrm{PaO}_{2} / \mathrm{FIO}_{2}\right.$ 156.4 \pm 43.9$)$. However, similar to the 
previous studies, survivors had lower APACHE II scores (14.5 \pm 2.6$)$ [44]. Pooled analysis on mortality rates associated with NIMV in mixed-ILD and IPF can be found in the supplementary material.

\section{Other risk factors}

Multiple risk factors have been evaluated in individual studies that have not been re-evaluated or have failed to replicate in others. Here, we present a brief summary of those that reached significance in multivariate analysis and were performed in large studies. In mixed-ILD patients, ZAFRANI and co-workers [28] identified that ILD-related pulmonary hypertension and computed tomography fibrosis were associated with a higher 12-month mortality (HR 3.21 (95\% CI 1.45-7.11) and 2.36 (95\% CI 1.05-5.32), respectively). Also, acute kidney injury (OR 10.60, 95\% CI 2.25-49.97) was found to be associated with in-hospital mortality, which is consistent with other studies in the critical care literature [48]. In IPF studies, ODA and co-workers [37] reported that cotrimoxazole (OR 0.28, 95\% CI 0.132-0.607) and macrolides (OR 0.37 , 95\% CI $0.155-0.867$ ) were independently associated with decreased mortality, although this finding has not been evaluated in other studies. Finally, SoNG and co-workers [41] found C-reactive protein and lymphocytes in the bronchoalveolar lavage fluid were associated with mortality risk after correcting for several factors (age, sex and $\mathrm{PaO}_{2} / \mathrm{FIO}_{2}$ ratio among others).

\section{Discussion}

Given the increasing availability of ICU care, evaluating what risk factors are associated with increased mortality becomes important to counsel patients and their families on likely outcomes. To our knowledge, this is the first systematic review that presents a thorough analysis on risk factors for mortality in patients with ILD in the ICU. While the small sample size and heterogeneity of many studies precluded the identification of statistically significant predictors of mortality or cause-effect relationships, some studies identified risk factors that may also indicate severity of disease. In patients with mixed-ILD, elevated APACHE score, hypoxaemia and mechanical ventilation were associated with increased mortality in the majority of the studies. In patients with IPF, only IMV was associated with increased mortality. Notably, while IMV is associated with overall poor prognosis, patient outcomes may be improved with lung protective strategies such as low PEEP and low tidal volumes, especially when there is a reversible condition. FERNANDEZ-PEREZ and co-workers [14] hypothesised that ILD patients may have limited recruitable lung. Thus, at higher PEEP, they were possibly experiencing over-distention injury, which was supported by elevated peak and plateau pressures [14]. Similarly, RANGAPPA and MORAN [3] suggest that high PEEP might be detrimental in IPF for the aforementioned reasons. However, high airway pressure may not necessarily cause injury if the pressure is from distending chest wall or collagen in the lung. Alternatively, as patients with severe hypoxaemia are given high PEEP, this might also represent an indicator of disease severity. This is why some authors suggest that IMV should be restricted to patients who can be eligible for lung transplant, which is an intervention that has been shown to improve mortality [49].

The use of steroids is still controversial. Our study did not find increased mortality associated with steroid use in patients with mixed-ILD. Their benefit likely depends on the underlying aetiology of ILD. Patients with steroid responsive diseases, such as hypersensitivity pneumonitis and CTD-ILD, probably derive benefit; this is likely untrue for IPF. Carefully designed clinical trials in various types of ILD are critically needed to assess the role of immunosuppression. The evidence on advance age is inconclusive, as positive and negative results have been reported in different studies. Regarding other factors in patients with IPF, evidence is also inconclusive for advanced age, elevated APACHE score and steroids use. The explanation of this phenomenon might rely not only on the size of the studies but also on the high mortality of IPF, which precludes a bivariate analysis. It is not clear why no association between hypoxaemia and mortality was found in three studies in IPF but the size of two studies was very small $(<20$ patients) and the third study $(\mathrm{n}=90)$ found an association in the bivariate but not the multivariate analysis. A potential explanation for this observation can be that the degree of hypoxaemia is severe in both survivors and nonsurvivors to find a significant difference. Therefore, this observation needs to be evaluated in large studies, as it is unexpected. Research in high flow nasal cannula has been proposed to be an alternative to conventional oxygen to correct hypoxaemia in patients with IPF [50] but the evidence is limited to series of cases on patients with interstitial pneumonias [51] and patients with do-not-intubate orders [52].

Our study also reports a down-trending mortality rate from 1993 to 2017 in patients with ILD (supplementary material e-table 3) which confirms the results from a recent large cohort study that reported decreased mortality from 2006 to 2012 in patients with IPF [53]. This observation could be explained by the role of new ventilation parameters such as low tidal volumes described in the acute respiratory distress syndrome network trial [54] and could explain its potential benefit in ILD. An alternative explanation could be secular trends in ICU care such as better haemodynamic management and aggressive antibiotic coverage. However, our calculation has limitations including the wide range of 
years included in the studies, different available interventions over time, and the fact that mortality in the mixed-ILD group does not represent non-IPF ILD population alone as it includes some patients with IPF. Notably, mortality increases with time post hospitalisation with rates of 54-96\% in mixed-ILD and $100 \%$ in IPF $[12,14,16,28]$. Thus, ICU admission with ILD appears to carry prognostic implications beyond the actual hospital stay. Our study also presents exploratory data on mortality and failure rates associated with NIMV and IMV over time. In mixed-ILD, the mortality rate associated with NIMV was $49 \%$ compared to $71 \%$ with IMV, and the failure rate of NIMV was 52\% (supplementary material). This observation can represent an indicator of less severity as patients who were offered NIMV could have had only mild or moderate disease. EsQuinas Rodriguez and FERRARI [55] postulate that NIMV can reduce alveolar stress during tidal ventilation by improving lung compliance and increasing functional residual capacity. Therefore, NIMV needs further research as our exploratory data and some studies suggest it can prevent intubation and reduce mortality in some patients $[18,25,35,44]$. Further discussion of this topic in patients with IPF can be found in the supplementary material.

This review has several limitations including the inclusion of retrospective studies of limited sample size, variable statistical analyses (including lack of multivariate modelling and lack of time-to-event analysis), heterogeneous subsets of ILD patients, and diverse evaluation of risk factors. We were not able to evaluate differences in populations over time given patient heterogeneity (in terms of underlying ILD, severity and treatments), different definitions for IPF used before the American Thoracic Society/European Respiratory Society guidelines were published [4], the inclusion of exacerbations caused by numerous aetiologies with different prognosis, and a wide overlap in the years included in each study. These limitations might have affected our results as some studies have conclusions in opposite directions, which made the evidence for some factors inconclusive. We should also highlight that mixed-ILD studies have the problem of combining patients with potentially worse prognosis such as IPF and others with conditions that might have a better prognosis such as CTD-ILD or drug-induced ILD [26]. Therefore, the findings presented in our manuscript should be interpreted with caution. However, we have to acknowledge that ILD is not a common disease and the current literature is only based, mainly, on series of cases. While some lessons are clear, this review highlights many remaining questions. Multi-centre cohort studies would be invaluable to enrol more patients over a short period of time, better characterise different types of ILD, detect geographical variations and help evaluate if emerging management therapies are affecting survival. The latter point is especially important in light of recent IPF and IIP guidelines $[5,6]$. Prospective trials are also needed, particularly to investigate ventilation strategies.

\section{Conclusions}

Irrespective of ILD aetiology, mechanical ventilation is associated with increased mortality. For mixed aetiology ILD, hypoxaemia and APACHE scores are also associated with increased mortality. No increased mortality was found with steroids use. IPF has the highest mortality rate among ILDs, but since 1993 the rate appears to be declining. Despite improving in-hospital survival, overall mortality remains high.

Conflict of interest: None declared.

Support statement: This study was supported by the Lisa Sandler Spaeth Fund for Pulmonary Fibrosis. The sponsor had no role on the conception of this work.

\section{References}

1 Danoff SK. Toward understanding patient experience in idiopathic pulmonary fibrosis. Eur Respir J 2017; 49: 1602202.

2 Collard HR, Ryerson CJ, Corte TJ, et al. Acute exacerbation of idiopathic pulmonary fibrosis. an international working group report. Am J Respir Crit Care Med 2016; 194: 265-275.

3 Rangappa P, Moran JL. Outcomes of patients admitted to the intensive care unit with idiopathic pulmonary fibrosis. Crit Care Resusc 2009; 11: 102-109.

4 Idiopathic pulmonary fibrosis: diagnosis and treatment. International consensus statement. American Thoracic Society (ATS), and the European Respiratory Society (ERS). Am J Respir Crit Care Med 2000; 161: 646-664.

5 Raghu G, Collard HR, Egan JJ, et al. An official ATS/ERS/JRS/ALAT statement: idiopathic pulmonary fibrosis: evidence-based guidelines for diagnosis and management. Am J Respir Crit Care Med 2011; 183: 788-824.

6 Raghu G, Rochwerg B, Zhang Y, et al. An Official ATS/ERS/JRS/ALAT clinical practice guideline: treatment of idiopathic pulmonary fibrosis. An update of the 2011 clinical practice guideline. Am J Respir Crit Care Med 2015; 192: e3-e19.

7 Mallick S. Outcome of patients with idiopathic pulmonary fibrosis (IPF) ventilated in intensive care unit. Respir Med 2008; 102: 1355-1359.

8 Bjoraker JA, Ryu JH, Edwin MK, et al. Prognostic significance of histopathologic subsets in idiopathic pulmonary fibrosis. Am J Respir Crit Care Med 1998; 157: 199-203.

9 Ghatol A, Ruhl AP, Danoff SK. Exacerbations in idiopathic pulmonary fibrosis triggered by pulmonary and nonpulmonary surgery: a case series and comprehensive review of the literature. Lung 2012; 190: 373-380.

10 Avnon LS, Pikovsky O, Sion-Vardy N, et al. Acute interstitial pneumonia-Hamman-Rich syndrome: clinical characteristics and diagnostic and therapeutic considerations. Anesth Analg 2009; 108: 232-237. 
11 Vourlekis JS, Brown KK, Cool CD, et al. Acute interstitial pneumonitis. Case series and review of the literature. Medicine (Baltimore) 2000; 79: 369-378.

12 Huie TJ, Olson AL, Cosgrove GP, et al. A detailed evaluation of acute respiratory decline in patients with fibrotic lung disease: aetiology and outcomes. Respirology 2010; 15: 909-917.

13 Churg A, Muller NL, Silva CI, et al. Acute exacerbation (acute lung injury of unknown cause) in UIP and other forms of fibrotic interstitial pneumonias. Am J Surg Pathol 2007; 31: 277-284.

14 Fernandez-Perez ER, Yilmaz M, Jenad H, et al. Ventilator settings and outcome of respiratory failure in chronic interstitial lung disease. Chest 2008; 133: 1113-1119.

15 Fumeaux T, Rothmeier C, Jolliet P. Outcome of mechanical ventilation for acute respiratory failure in patients with pulmonary fibrosis. Intensive Care Med 2001; 27: 1868-1874.

16 Gaudry S, Vincent F, Rabbat A, et al. Invasive mechanical ventilation in patients with fibrosing interstitial pneumonia. J Thorac Cardiovasc Surg 2014; 147: 47-53.

17 Goncalves AF, Campainha S, Nogueira C, et al. Interstitial lung disease in the intensive unit care setting. Rev Port Pneumol (2006) 2016; 22: 179-180.

18 Gungor G, Tatar D, Salturk C, et al. Why do patients with interstitial lung diseases fail in the ICU? A 2-center cohort study. Respir Care 2013; 58: 525-531.

19 Martinez FE, Panwar R, Kelty E, et al. Idiopathic interstitial pneumonia in the ICU: An observational cohort study. Anaesth Intensive Care 2015; 43: 707-711.

20 Molina-Molina M, Badia JR, Marin-Arguedas A, et al. [Outcomes and clinical characteristics of patients with pulmonary fibrosis and respiratory failure admitted to an intensive care unit. A study of 20 cases]. Med Clin (Barc) 2003; 121: 63-67.

21 Olson AL, Huie TJ, Groshong SD, et al. Acute exacerbations of fibrotic hypersensitivity pneumonitis: a case series. Chest 2008; 134: 844-850.

22 Osman N, Sharkawy S, Gomaa A. Outcome of patients with interstitial lung diseases admitted to the respiratory intensive care unit. Egypt J Bronchol 2017; 11: 134-140.

23 Park IN, Kim DS, Shim TS, et al. Acute exacerbation of interstitial pneumonia other than idiopathic pulmonary fibrosis. Chest 2007; 132: 214-220.

24 Tachikawa R, Tomii K, Ueda H, et al. Clinical features and outcome of acute exacerbation of interstitial pneumonia: collagen vascular diseases-related versus idiopathic. Respiration 2012; 83: 20-27.

25 Tomii K, Tachikawa R, Chin K, et al. Role of non-invasive ventilation in managing life-threatening acute exacerbation of interstitial pneumonia. Intern Med 2010; 49: 1341-1347.

26 Vial-Dupuy A, Sanchez O, Douvry B, et al. Outcome of patients with interstitial lung diseases admitted to the intensive care unit. Sarcoidosis Vasc Diffuse Lung Dis 2013; 30: 134-142.

27 Yokoyama T, Tsushima K, Yamamoto H, et al. Potential benefits of early continuous positive pressure ventilation in patients with rapidly progressive interstitial pneumonia. Respirology 2012; 17: 315-321.

28 Zafrani L, Lemiale V, Lapidus $\mathrm{N}$, et al. Acute respiratory failure in critically ill patients with interstitial lung disease. PLoS One 2014; 9: e104897.

29 Akira M, Hamada H, Sakatani M, et al. CT findings during phase of accelerated deterioration in patients with idiopathic pulmonary fibrosis. AJR Am J Roentgenol 1997; 168: 79-83.

30 Al-Hameed FM, Sharma S. Outcome of patients admitted to the intensive care unit for acute exacerbation of idiopathic pulmonary fibrosis. Can Respir J 2004; 11: 117-122.

31 Ambrosini V, Cancellieri A, Chilosi M, et al. Acute exacerbation of idiopathic pulmonary fibrosis: report of a series. Eur Respir J 2003; 22: 821-826.

32 Blivet S, Philit F, Sab JM, et al. Outcome of patients with idiopathic pulmonary fibrosis admitted to the ICU for respiratory failure. Chest 2001; 120: 209-212.

33 Kim DS, Park JH, Park BK, et al. Acute exacerbation of idiopathic pulmonary fibrosis: frequency and clinical features. Eur Respir J 2006; 27: 143-150.

34 Kondoh Y, Taniguchi H, Kawabata Y, et al. Acute exacerbation in idiopathic pulmonary fibrosis. Analysis of clinical and pathologic findings in three cases. Chest 1993; 103: 1808-1812.

35 Mollica C, Paone G, Conti V, et al. Mechanical ventilation in patients with end-stage idiopathic pulmonary fibrosis. Respiration 2010; 79: 209-215.

36 Nava S, Rubini F. Lung and chest wall mechanics in ventilated patients with end stage idiopathic pulmonary fibrosis. Thorax 1999; 54: 390-395.

37 Oda K, Yatera K, Fujino Y, et al. Efficacy of concurrent treatments in idiopathic pulmonary fibrosis patients with a rapid progression of respiratory failure: an analysis of a national administrative database in Japan. BMC Pulm Med 2016; 16: 91.

38 Papiris SA, Kagouridis K, Kolilekas L, et al. Survival in idiopathic pulmonary fibrosis acute exacerbations: the non-steroid approach. BMC Pulm Med 2015; 15: 162.

39 Parambil JG, Myers JL, Ryu JH. Histopathologic features and outcome of patients with acute exacerbation of idiopathic pulmonary fibrosis undergoing surgical lung biopsy. Chest 2005; 128: 3310-3315.

40 Saydain G, Islam A, Afessa B, et al. Outcome of patients with idiopathic pulmonary fibrosis admitted to the intensive care unit. Am J Respir Crit Care Med 2002; 166: 839-842.

41 Song JW, Hong SB, Lim CM, et al. Acute exacerbation of idiopathic pulmonary fibrosis: incidence, risk factors and outcome. Eur Respir J 2011; 37: 356-363.

42 Stern JB, Mal H, Groussard O, et al. Prognosis of patients with advanced idiopathic pulmonary fibrosis requiring mechanical ventilation for acute respiratory failure. Chest 2001; 120: 213-219.

43 Vianello A, Arcaro G, Battistella L, et al. Noninvasive ventilation in the event of acute respiratory failure in patients with idiopathic pulmonary fibrosis. J Crit Care 2014; 29: 562-567.

44 Yokoyama T, Kondoh Y, Taniguchi H, et al. Noninvasive ventilation in acute exacerbation of idiopathic pulmonary fibrosis. Intern Med 2010; 49: 1509-1514.

45 Knaus WA, Draper EA, Wagner DP, et al. APACHE II: a severity of disease classification system. Crit Care Med 1985; 13: 818-829.

46 Hutchinson JP, McKeever TM, Fogarty AW, et al. Surgical lung biopsy for the diagnosis of interstitial lung disease in England: 1997-2008. Eur Respir J 2016; 48: 1453-1461. 
Donahoe M, Valentine VG, Chien N, et al. Autoantibody-targeted treatments for acute exacerbations of idiopathic pulmonary fibrosis. PLoS One 2015; 10: e0127771.

48 Case J, Khan S, Khalid R, et al. Epidemiology of acute kidney injury in the intensive care unit. Crit Care Res Pract 2013; 2013: 479730 .

49 Thabut G, Mal H, Castier Y, et al. Survival benefit of lung transplantation for patients with idiopathic pulmonary fibrosis. J Thorac Cardiovasc Surg 2003; 126: 469-475.

50 Faverio P, De Giacomi F, Sardella L, et al. Management of acute respiratory failure in interstitial lung diseases: overview and clinical insights. BMC Pulm Med 2018; 18: 70.

51 Horio Y, Takihara T, Niimi K, et al. High-flow nasal cannula oxygen therapy for acute exacerbation of interstitial pneumonia: a case series. Respir Investig 2016; 54: 125-129.

52 Koyauchi $\mathrm{T}$, Hasegawa $\mathrm{H}$, Kanata $\mathrm{K}$, et al. Efficacy and tolerability of high-flow nasal cannula oxygen therapy for hypoxemic respiratory failure in patients with interstitial lung disease with do-not-intubate orders: a retrospective single-center study. Respiration 2018: 1-7.

53 Rush B, Wiskar K, Berger L, et al. The use of mechanical ventilation in patients with idiopathic pulmonary fibrosis in the United States: a nationwide retrospective cohort analysis. Respir Med 2016; 111: 72-76.

54 Brower RG, Matthay MA, Morris A, et al. Ventilation with lower tidal volumes as compared with traditional tidal volumes for acute lung injury and the acute respiratory distress syndrome. N Engl J Med 2000; 342: 1301-1308.

55 Esquinas Rodriguez AM, Ferrari G. Non-invasive mechanical ventilation in acute exacerbation of interstitial pneumonia: David versus Goliath? Respirology 2012; 17: 1152. 